\title{
Introduction to an Architectural Theory: Design as Theory Application
}

\author{
Harsha Munasinghe
}

\begin{abstract}
Architect is not commissioned to do research, but to design. At his/her best, the architect may look at some built environments in the name of precedent studies. Debate whether architect need to do research or could the designing be theory application is growing. This paper aims at introducing truism of the disciplinary model, which is implicitly used in architectural research but seldom openly studied in philosophy of architecture. The key question is, whether theories of architecture are vehicles which the basis of the truism, the analogy from natural sciences, entails and whether relativity can be excluded from applying to architectural reality, as it seems to be done presently. At its best, truism may bring life to the dusty ghosts of the past and at its worst, forms a vicious circle of implicit rules of interpretation, a conspiracy of proper attitude passionately governed by gurus and adherents. First, the disciplinary model is described and examples given to exemplify its role in history writing. Finally, we conclude with remarks on the implications of the discussed disciplinary model.
\end{abstract}

\section{Introduction: Disciplinary Model of Architecture}

We architects believe in creating a space that is intelligible to its reader. We want our clients to perceive our space, understand our language, so that they would be happy and content in the spaces created for them. At the same time, as true artists, we intend to communicate a message through our work of artspaces, perhaps a message of the society, or economy, or even of the future that lies ahead of them. If they comprehend all these, then they may, or at least we say, they dwell the space (Heidegger 1971:143). Le Corbusier noted his noble duty of making India a modern nation state through designing the City of Chandighar. One may question if his intentions was fulfilling such a duty or if it was just trying a model perfected by the pioneer of modernism him for his own enjoyment. This is where our research problem lies: the discipline of architecture.

In order to make the user intelligible, an architect may first elaborate visible exemplars of time, works and authors and then, compare this data with contemporary, invisible ideas and structures of thoughts. The final touch can be made by postulating a more general, conditions such as cultural or social background (Broadbent, 1988: xxii). The discipline of architecture is thus comprised concretely of the existing buildings and the environment they form. Architecture comprehends also the invisible side- the environmental models or pictures that are carried by architect- architect consciously or subconsciously in thinking of dreams. Finally, architecture entails a paradigm, an architectural world view, the magic hand which creates styles and schools and is associated with such issues as natural sciences philosophy or cultural climate.

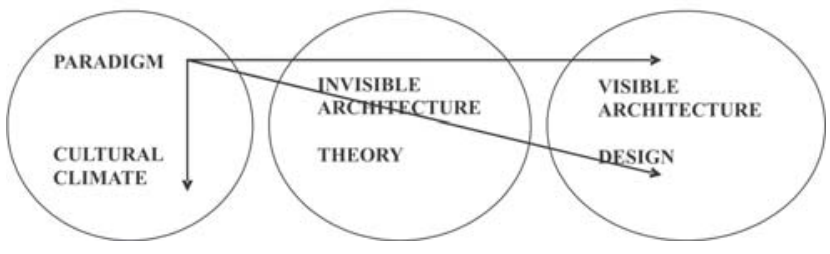

\section{Interpreting the Renaissance}

Italian Renaissance is considered by many as a good example for an architectural theory. Alberti, rejecting the idea that architecture was simply applied mathematics as noted by Vitruvius, established certain principles postulated into reasons, on service to patrons, and on the manipulation of the materials and construction techniques. Alberti introducing the idea of central church, which was unsatisfactory from a liturgical point of view, has led some historians to emphasize the irreligious or worldly aspects of Renaissance (Westtal, 1982:1-1). Contemporary cultural ideas provide elucidating frames for proper understanding in the Renaissance divine perfection no longer consisted in the transcendence of nature, but was found in nature itself. Human creativity was given an importance which approached the creative power of God himself. In this sense the Renaissance quest for harmony and beauty, as well as the reintroduction of classical order were means to endow buildings with divine beauty (Norberg-Schulz, 1975:115,128). As Rudolf Wittkower (1949:3) notes, A new discussion of the ideas underlying ecclesiastical architecture during the Renaissance will, it is hoped, clear the ground for a more correct understanding of the architect's intension 
and, at the same time, help to elucidate the element of tradition in some important currents of Renaissance thought.

The logic beyond this kind of thinking is the following firstly, theory is registered as a literal expression of 'invisible architecture' and it is thus presumed to provide in a way an easily accessible route to contemporary architectural ideas in an 'pre-objectified' condensed and explicit format. Secondly, if the theory seems incommensurate or fails to explain certain aspects of 'visible architecture', the enlargement on the context with aspects of contemporary cultural climate (for Alberti, the concept of God) provide further backing up. Consequently, if a whole era is in the focus of interest, the most elucidatory or explicatory aspects which constitute the 'theme' or the touchstone of that era are compared with antecedent and successive ages. In that way, Renaissance architecture gains a typology in a form of a list of the most relevant concepts like 'man', 'wall', 'circle', symmetry', 'beauty\, 'harmony', etc. As a result, the methodological golden rule seems to be something like as the theory- as the basis of practiceimplies a commitment to certain kind of applications. Albertils application was ontologically very different from Vitruvius', yet both worked under a different architectural paradigm.

\section{Philosophical Arguments}

The philosophical foundations for this kind of an approach can be found from Thomas Kuhn's theory presented in 1962. His central phrase normal science refers to “... research firmly based on one or more past scientific achievements, that some particular scientific community acknowledge for a time as supplying the foundation for its further practice" (Kuhn, 1962: 10). Its foundations are in a paradigm, the predominant conception of a discipline which has legitimate, institutional position. Paradigm thus gives form to scientific life and function as a vehicle for scientific theory, by telling the scientist of the entities that nature does and does not contain and about the ways those entities behave. That information provides a map whose details are elucidated by mature scientific research. Through the theories they embody, paradigms prove to be constitutive of the research activity. When paradigms change, there are significant shifts in the criteria determining the legitimacy both of problems and of proposed solutions (ibid: 109).

However, Kuhn's theory implies that if a paradigm is a set of premises, then the theories of normal science are vehicles, not valid or invalid as such, and values are extraneous to science. Larry Laudan (1984:67-102) notes that the tunnel vision of historical record brings us to fallacy of believing that changes in values, methodology or paradigm are isomorphic. Therefore they enhance the importance of the concession in Kuhn's 1969 postscript to the said theory: there is no neutral algorithm for theory-choice, no systematic decision procedure which properly applied, must lead (after certain phases) each individual in the group of scientists to the same decision (Kuhn, 1962: 70).

The term paradigm is actually two-fold: on one hand, it stands for the entire constellation of values, beliefs, metaphysical premises and symbolical generalizations, shared by the members of a given community, and on the other, it denotes exemplary past achievements used as model puzzle solutions (Kuhn, 1962:175). The first definition, the interpretation of the term paradigm as an objective set of fuzzy elements of a culture, is presumably one of the major reasons for criticism by Kuhn's successors and the core fallacy in architectural epistemology today. In architectural domain, the disciplinary model leads architectural research to failure as to validity, or optionally, leads to success only if the truth value of data is intrinsically 'negotiable'. The remark is commensurate with Laudan's (1984:73-79) statement that "... the various components of a world view are individually negotiable and individually replaceable in a piecemeal fashion". Either are personal preferences of the historian or the personal preferences of the antecedent architect abstracted to match the paradigm. The paradigm (the concept which, according to Kuhn, should be a predominant conception with a legitimate, institutional position) is in architecture as an arbitrary, almost capricious postulation of most explicatory or most relevant factors of a general climate, but simultaneously an ideological omission of incommensurate factors (i.e. problem with early modernist historians) in order to best support the hypothesis of the historian (Curtis, 1982: 10, Mandrous, 1978: 11).

\section{Implications of Theories}

If values are present through out in a discipline, then any element of the discipline implies assessments and hence to the very deeply value-laden aspect of any kind of theory. Thus, theories of architecture are not vehicles for architectural works but vehicles for subscribing to certain world views- for objective realism, cultural conventionalism or the idea of a mutual origin. Scientific knowledge of architectural profession is embedded not in rules or theories, but in way of viewing situations (Kuhn, 1962:187-191). The writings of architecture, claimed to be theories or conceptual models of theories of architecture, one may suspect, as mere ideological manifestations (Munasinghe, 2003).

According to Alan Colquhoun architectural theory has always been based implicitly upon one of two interpretations of history. On one hand, it has been held within the normative view of history that history is the repository of permanent values transmitted from one generation to the next in the form of myths and apodictic truths, accompanied with a belief in a golden age in which those values were manifest in a pure form. On the other hand, there is the relativistic view of history, in which it has been held that history is a process of evolution where each epoch erects its own self- 
justificatory system of values which entails the positivistic vision of a utopian future (Colquhoun, 1981:11). He further states that although architecture does not imitate the external world, it attaches itself to this world through our experience or our knowledge of buildings and become signs of other things (Ibid: 193). The synthesis of both approaches is therefore needed, and to Colquhoun hermeneutics of traditions serves best for the purpose. However, despite of good intensions in hermeneutics, the dialogue between the interpreter and object, its language-game and its associated view of the world "... is not a cab which one can get in and out of at will" (Outhwaite, 1995: 34). In other words, the suggested multipoint strategy which establishes architectural meanings to the fusion of custom and law does not provide any more stability, validity or constancy than a single-point strategy, because none of the cornerstones, the idea of the world in the past, in the present nor in the future, is objective, constant or stable.

Jencks (1973:11-13) was partly correct in his opposition to both Zeitgeist theory and the single strand theory, and his remarks on the effect of the historians methodology, profession and ideology on architectural history is a very apposite one. Similarly, the interpretative license to architectural history is valid, since "the faculty of abstraction and gentrification, or induction, is the basic distinction of man, and the experience of meaning his basic needs" (NorbergSchulz, 1975:221). According to Colquhoun (1961:11), "a positivistic interpretation of culture is just as dependent on metaphoric displacement as a mythological one, and it is therefore equally in need of demystification". The simultaneous validity, and fallacy, of both controversial viewpoints- polarized into the exemplars by Jencks and Norberg-Schulz- gives an insight into something deeply fundamental in architecture's genre.

\section{Discussion}

We place emphasis on Kuhn's second aspect of paradigm: the idea of tacit knowledge in architecture. In essence, it suggests treating architecture as intentional human action that architecture is somehow "sign of other things", and valid theory means a model of that sign system between the architect and the user or the perceiver describing it as well as possible. Where Vitruvius did it Orders and by enhancing architect's multidisciplinary competence, Le Corbusier did it with the Five Points and by enhancing architect's artistic competence. In short, to perceive architecture, we cherish a fiction of order of the way in which all actors of a wonderful system of architecture take their place in the magnificent play of meanings.

Does the idea of architecture as an intentional act justify the architect to undertake a didactic assignment? If it does, then we must face the paradox with the causality of meaning, the idea of linearity, and consequently disagree with the presumption that architecture can transmit meanings from its creator to its perceiver. We shall note the seriousness of Colquhoun (1981:17) “... the role of architect is reduced to that of a purveyor of signs", without discarding the symbolic meanings of architecture.

This directs us to a set of questions. Is this already happening? Are we architects playing this role through our designs? Most importantly, will our clients pay for this?

\section{Reference}

Broadbent, Geoffrey (1988) Design in Architecture: Architecture and the Human Science, London: David Fulton

\section{Colquhoun, Allan (1981) Essays in Architectural Criticism: Modern Architecture and Historical Change, MIT Press: Opposition Books}

\section{Curtis, William (1987) Modern Architecture since 1900,} Oxford: Phaidon

Heidegger, Martin (1971)- Poetry, language and Thought, (translated by Albert Hofstadter in 1973) New Tork: Harper Colophon Books

Jencks, Charles (1977) Modern Movements in Architecture, London: Penguin Books

Kuhn, Thomas (1962) The Structure of Scientific Revolution, Chicago: Chicago University Press

Laudan, Larry (1984) Science and Values, Berkley: University of California

Lang, Jon (1987) Creating Architectural Theory, New York: Van Nostrad Reinhold

Mandrou, Robert (1979) From Humanism to Science, New Jersey: Humanities Press

\section{Norberg-Schulz, Christian (1977) Meaning in Architecture, London: Studio Vista}

Skinner, Quentin (1985) (ed.) The Return of Grand Theory in the Human Science, Cambridge: Cambridge University Press

Vitruvius (1914) Ten Books on Architecture (trans. Morris Hicky Morgan) New York: Dover publications

Wiebenson, Dora (1982) (ed.) Architectural theory from Alberti to Ledoux London: Architectural Publications

Witkower, Rudolf (1949) Architectural Principles in the Age of Humanism London: Academy editions 